\title{
PATOGENICIDADE DO FUNGO Colletotrichum gloeosporioides, PATÓGENO DA COCHONILHA Orthezia praelonga, A DIVERSOS FRUTOS E A PLÂNTULAS DE ABOBRINHA ${ }^{1}$
}

\author{
MANOEL ARAÚJO TEIXEIRA²; WAGNER BETTIOL ${ }^{3}$; ROBERTO CESNIK ${ }^{3}$; ROSANA FARIA VIEIRA ${ }^{3}$
}

\begin{abstract}
RESUMO - A descoberta do fungo Colletotrichum gloeosporioides parasitando cochonilha em pomares cítricos levantou a possibilidade de sua utilização no controle de Orthezia praelonga. O controle biológico, porém, deve ser feito com a certeza de que o microrganismo utilizado não ocasionará doenças em outras culturas. Este trabalho teve por objetivo avaliar e comparar o potencial fitopatogênico dos isolados de $C$. gloeosporioides patogênicos a $O$. praelonga, com outros isolados de $C$. gloeosporioides, $C$. acutatum e $C$. lagenarium, responsáveis pelas doenças de pós-colheita e podridão floral, em citros, e da antracnose, em abobrinha, respectivamente. Os fungos foram inoculados em banana, café, maçã, mamão, pêssego e folhas de abobrinha, com e sem ferimentos. Os pêssegos foram suscetíveis a todos os isolados testados, nas duas metodologias utilizadas. As maçãs e as folhas de abobrinha, quando lesadas, também mostraram suscetibilidade. A banana, o café e o mamão não foram suscetíveis em nenhum dos métodos de inoculação.
\end{abstract}

Termos para indexação: controle biológico, praga, doença de plantas

\section{PATHOGENICITY OF THE FUNGUS Colletotrichum gloeosporioides, PATHOGEN OF Orthezia praelonga, TO SEVERAL FRUITS AND TO PUMPKIN SEEDLINGS}

\begin{abstract}
The discovery of the fungus Colletotrichum gloeosporioides living like a parasite on the $O$. praelonga in citric orchards, raise the possibility of its utilization on the control of this pest. The biological control, however, should be done with the certainty that the utilized microorganism will not provoke diseases in other cultures that are been cultivated near the orchards. Then, this work aimed to evaluate and compare the phytopathogenic potential of the $C$. gloeosporioides isolates, pathogenics of $O$. praelonga $\left(\mathrm{CTAA}_{1-5}\right)$, with other $C$. gloeosporioides isolates (CCC and CCE), C. acutatum (CCA) and C. lagenarium, responsible by diseases of fruit in citrus post-harvest and postbloom, and by antracnose in pumpkin, respectively. The fungi were inoculated on banana, coffee, apple, peach, papaya and on the pumpkin leaves, with or without injury. The peach fruits were susceptive to all isolates tested at the two experimental conditions. The apple and the pumpkin leaves, when injured, also showed susceptibility. The banana, coffee, and papaya were not susceptive in both inoculation conditions.
\end{abstract}

Index terms: biological control, pest, plant disease

A cochonilha Orthezia praelonga Douglas (1981), causa danos diretos e indiretos à citricultura. Como consequiência, os frutos caem prematuramente ou se tornam "aguados", de tamanho reduzido e com baixos teores de açúcares e ácidos. Vários testes com inseticidas já foram realizados na tentativa de controlar a cochonilha, mas os resultados foram somente paleativos. Esses produtos podem contaminar os frutos cítricos e o ambiente. O controle biológico, utilizando o fungo Colletotrichum gloeosporioides (Penz.), patógeno da cochonilha $O$. praelonga, tem se mostrado eficiente (Cesnik \& Ferraz, 2000) e pode ser uma alternativa de controle da praga. Poucos são, porém, os trabalhos encontrados na literatura sobre o potencial fitopatogênico de $C$. gloeosporioides, patógeno de $O$. praelonga, no ambiente. Cesnik \& Oliveira (1993) verificaram a sua patogenicidade em folhas de Cocoloba sp., evidenciando a necessidade de realização de testes similares com outros hospedeiros, principalmente, tecidos cítricos. Teixeira et al. (2001) observaram a patogenicidade deste fungo em frutos destacados e em flores de citros, em experimento conduzido em casa de vegetação. $\mathrm{O}$ objetivo deste trabalho foi verificar a patogenicidade do fungo $C$. gloeosporioides, patógeno de $O$. praelonga, a folhas cotiledonares de abobrinha e à banana, ao café, ao mamão, à maçã e ao pêssego.

O experimento para avaliação da patogenicidade de $C$. gloeosporioides a plântulas de abobrinha (Curcubita pepo variedade Caserta) foi conduzido em casa de vegetação, em um delineamento inteiramente casualizado, com seis repetições, testando nove diferentes isolados de Colletotrichum: $\mathrm{CTAA}_{1}, \mathrm{CTAA}_{2}, \mathrm{CTAA}_{3}, \mathrm{CTAA}_{4} \mathrm{e} \mathrm{CTAA}_{5}$ - isolados patogênicos a $O$. praelonga; $\mathrm{CCC}$ e CCE - isolados de plantas de citros e identificados como C. gloeosporioides, agente causal da antracnose em pós-colheita; CCA - C. acutatum, agente causal da podridão floral dos citros; e $\mathrm{CL}-C$. lagenarium, agente etiológico da antracnose em abobrinha. Em vasos plástico de três litros contendo substrato [Latossolo Vermelho-Escuro (LE) e esterco bovino compostado $(5: 1 \mathrm{v} / \mathrm{v})]$ foram semeadas três sementes e mantidas duas plântulas após o desbaste. Aos nove dias da semeadura, foi realizada a inoculação nas folhas cotiledonares, com e sem ferimento, com agulhas múltiplas. Os inóculos dos fungos constituíram-se de uma suspensão de $1 \times 10^{6}$ conídios $\mathrm{mL}^{-1}$, que foram aspergidos na superfície foliar. No tratamento-testemunha, utilizou-se água destilada esterilizada. As plantas foram mantidas em câmara úmida por 24 horas e avaliadas aos 6 dias após a inoculação. A avaliação das folhas, foi feita pela incidência de lesões foliares, utilizando-se de uma escala diagramática, baseada na severidade da doença ( 1 - folhas totalmente sadias; 2 - folhas com sintomas em até $25 \%$ da área injuriada; 3 - de $26 \%$ até $50 \%$ da área injuriada; 4 - de $51 \%$ até $100 \%$ da área injuriada, e 5-100\% da área injuriada + sintomas da área não injuriada). As folhas sem ferimento foram avaliadas somente pela incidência ou não da doença. Duas folhas com os sintomas da doença foram utilizadas para o reisolamento dos fungos, em cada tratamento, de modo a comprovar a sobrevivência do inóculo.

Os testes para avaliação da patogenicidade de $C$. gloeosporioides, patógeno de $O$. praelonga, em banana (cultivar Nanica), café (Cultivar Catuaí Vermelho), mamão (cultivar Papaya), maçã (cultivar Gala) e pêssego (cultivar Chimarrita), foram realizados utilizando-se dos isolados $\mathrm{CTAA}_{1}, \mathrm{CTAA}_{4}, \mathrm{CTAA}_{5}, \mathrm{CCC}_{\mathrm{e}} \mathrm{CCA}$. O experimento consistiu de dois métodos de inoculação: frutos injuriados até a polpa com um conjunto de agulhas e frutos não injuriados. Para cada isolado e para cada método de inoculação, foram feitas 10 repetições por variedade estudada. Antes da inoculação, os frutos foram desinfestados com hipoclorito de sódio a $0,5 \%$ e enxaguados por 2 vezes. Discos de $0,7 \mathrm{~mm}$ de diâmetro foram utilizados para a banana, maçã, mamão e pêssego, como fonte de inóculo. Para o café, o inóculo foi feito conforme descrito para as folhas de abobrinha. As testemunhas foram pulverizadas com

\footnotetext{
${ }^{1}$ (Trabalho 159/2003). Recebido: 22/10/2003. Aceito para publicação: 12/07/2004. Parte da tese de Mestrado do primeiro autor apresentada à UNESP, Botucatu-SP ${ }^{2}$ UNIVÁS-Universidade do Vale do Sapucaí, CP 213, CEP 37550-000, Pouso Alegre-MG. Biólogo (035-34492121) teixeira@cnpma.embrapa.br

${ }^{3}$ EMBRAPA - Embrapa Meio Ambiente, CP 69, CEP 13820-000, Jaguariúna-SP. Eng ${ }^{\circ}$ Agrônomos (019-38678700) bettiol@cnpma.embrapa.br, cesnik@cnpma.embrapa.br, rosana@cnpma.embrapa.br
} 
água destilada. $\mathrm{O}$ material inoculado foi mantido em câmara úmida por 24 horas, temperatura entre 24 e $26^{\circ} \mathrm{C}$, fotofase de 10 h e UR média de $80 \%$. A avaliação da patogenicidade dos fungos foi feita medindo-se o diâmetro médio das lesões de dois em dois dias, durante uma semana.

Os ferimentos foram determinantes na patogenicidade dos isolados de C. gloeosporioides, patógeno de O. praelonga, às folhas cotiledonares de abobrinha. Os isolados $\mathrm{CTAA}_{2,4 \text { e } 5}$ induziram severidades em escala 4 e $5 \mathrm{em}$, aproximadamente, $94 \%$ das folhas (Figura 1). O isolado CTAA induziu severidades entre 4 e 5 em $75 \%$ das folhas, enquanto o $\mathrm{CTAA}_{3}$ induziu severidade $4 \mathrm{em} 67 \%$ das folhas (Figura 1). A baixa patogenicidade do isolado CL pode ser atribuída a excessos de manuseios no laboratório. Nas folhas sem ferimentos, o CCA foi o isolado que apresentou maior porcentagem de doença, com uma incidência de $41,6 \%$ (Figura 2). Para os isolados de Colletotrichum, patogênicos a $\mathrm{O}$. praelonga, com exceção do $\mathrm{CTAA}_{3}$ e os CCC e CCE, a incidência da doença foi baixa. Esses resultados demonstram a pequena capacidade dos isolados de C. gloeosporioides em penetrar no tecido das folhas jovens de abobrinha, ao contrário do ocorrido com o CCA. A recuperação dos isolados $\mathrm{CTAA}_{1}-{ }_{5}$, CCC e CCE em meio de cultura foi elevada, o que demonstra que as lesões desenvolvidas nos tecidos foram causadas pelos isolados inoculados.

Nenhum dos isolados foi patogênico à banana, ao mamão, à

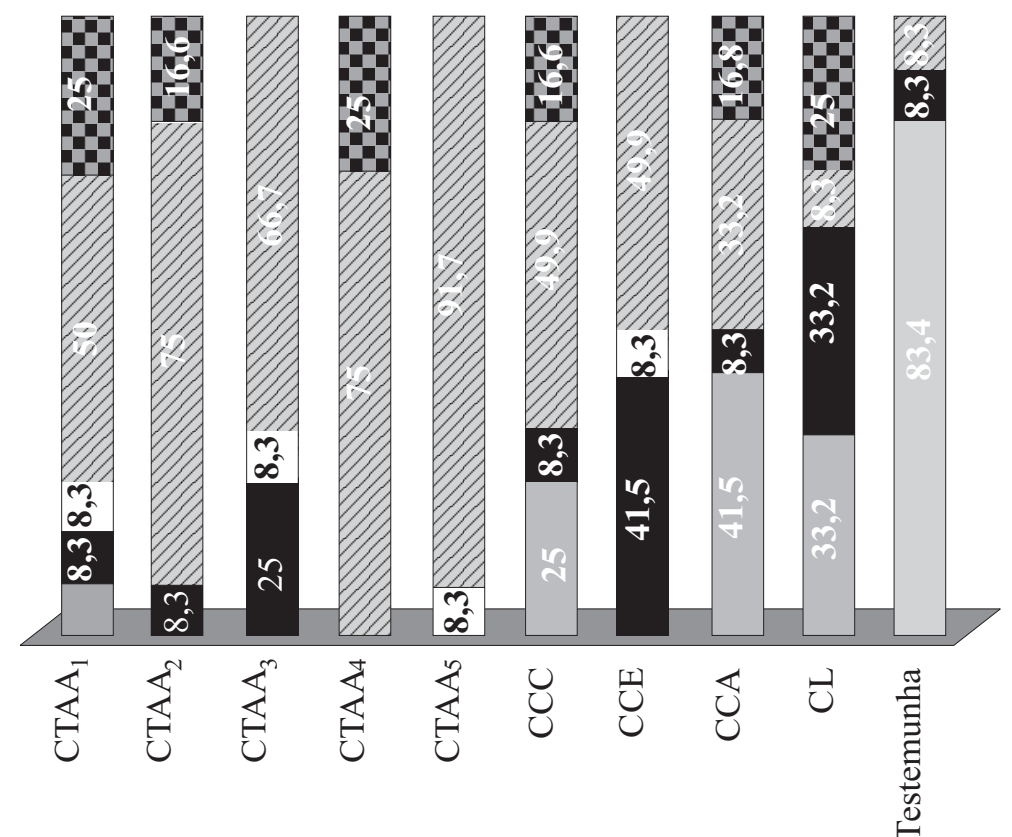

FIGURA 1 - Severidade de isolados de Colletotrichum gloeosporioides, patógenos de Orthezia praelonga, a folhas cotiledonares de abobrinha, com ferimentos. CTAA ${ }_{1},{ }_{2},{ }_{3},{ }_{5}-\mathrm{C}$. gloeosporioides agente de controle biológico da $\mathrm{O}$. praelonga; $\mathrm{CCC}$ e CCE - C. gloeosporioides agente causal de doenças de pós-colheita em citros; CCA - C.acutatum agente causal da podridão floral dos citros, e CL - C. lagenarium agente causal antracnose em abobrinha. Escala dagramática: $\square$ - folhas sadias; $\square$ - folhas com $25 \%$ da área injuriada; $\square$ - folhas com $26 \%$ a $50 \%$ da área injuriada; $\not Z^{-}$ folhas com $51 \%$ a $100 \%$ da área injuriada, e folhas com $100 \%$ de doença na área injuriada + área não injuriada.

maçã e ao café, quando inoculados sem ferimentos. Dos frutos que sofreram ferimentos, somente a maçã e o pêssego foram suscetíveis aos isolados inoculados. Esse resultado é importante, em especial para o café, considerando-se que esta cultura é mencionada como hospedeira de O. praelonga. No pêssego, os sintomas consistiram de uma necrose marrom e circular na casca e um apodrecimento da polpa. As lesões induzidas pelos isolados CTAA $_{1,4,5}$ foram de $1,56 \mathrm{~cm}$ de diâmetro, em média, enquanto para o CCC e para o CCA, elas foram de 1,36 e 1,16 cm de diâmetro, respectivamente (Tabela 1). Para as maçãs, as lesões desenvolvidas foram de 1,39; 1,43 e 1,27cm de diâmetro, respectivamente, para os isolados CTAA, CCC e CCA(Tabela 1). Os sintomas observados foram manchas pardas ou marrom-claras na casca e na polpa. A patogenicidade dos isolados de C. gloeosporioides, patógenos da $\mathrm{O}$. praelonga, na maçã e no pêssego, alerta para os cuidados da utilização destes fungos em pomares cítricos infestados com a cochonilha, situados próximos àquelas culturas, uma vez que seus frutos se mostraram suscetíveis.

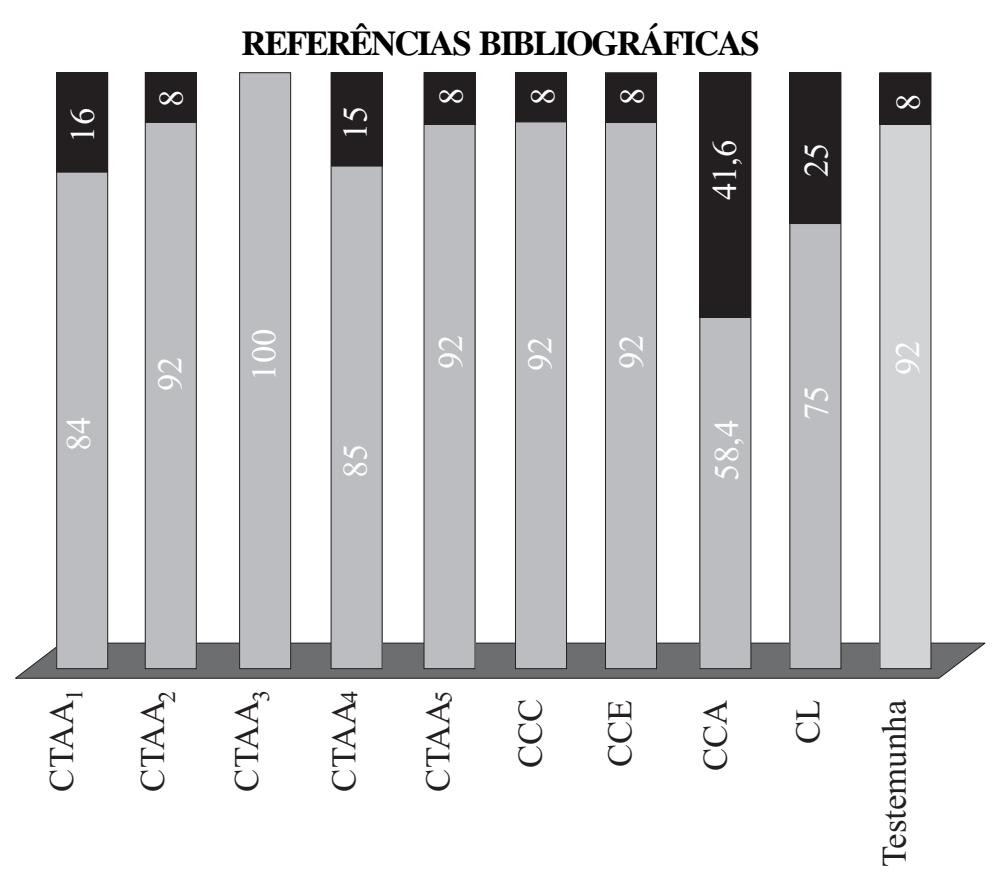

FIGURA 2 - Potencial patogênico dos isolados de Colletotrichum gloeosporioides, patógenos da Orthezia praelonga, a folhas cotiledonares de abobrinha. Porcentagem de doença em folhas sem ferimentos. CTAA ${ }_{1,2},{ }_{3},{ }_{4}, 5-C$. gloeosporioides agente de controle biológico da $O$. praelonga; CCC e CCE C. gloeosporioides agente causal de doenças de pós-colheita em citros; CCA - C.acutatum agente causal da podridão floral dos citros, e CL $-C$. lagenarium agente causal antracnose em abobrinha. Escala diagramática: $\square$ folhas doentes, $\square$ folhas sadias.

TABELA 1 - Diâmetro $(\mathrm{cm})$ médio das lesões nos frutos inoculados com isolados de Colletotrichum.

\begin{tabular}{cccc}
\hline Isolados & $\begin{array}{c}\text { Maçã } \\
\text { Com Ferimento }\end{array}$ & $\begin{array}{c}\text { Pêssego } \\
\text { Com Ferimento }\end{array}$ & $\begin{array}{c}\text { Pêssego } \\
\text { Sem Ferimento }\end{array}$ \\
\hline CTAA $_{1}$ & $1,46 \pm 0,07^{1}$ & $1,50 \pm 0,06$ & $0,47 \pm 0,13$ \\
CTAA $_{4}$ & $1,48 \pm 0,04$ & $1,69 \pm 0,11$ & $0,78 \pm 0,11$ \\
CTAA $_{5}$ & $1,22 \pm 0,04$ & $1,50 \pm 0,08$ & $0,26 \pm 0,10$ \\
CCC & $1,43 \pm 0,10$ & $1,36 \pm 0,12$ & $0,78 \pm 0,18$ \\
CCA & $1,27 \pm 0,06$ & $1,16 \pm 0,09$ & $0,14 \pm 0,09$ \\
Testemunha & 0,0 & 0,0 & 0,0 \\
\hline
\end{tabular}

${ }^{1}$ Desvio-padrão

$\mathrm{CTAA}_{1}, \mathrm{CTAA}_{4}$ e CTAA $_{5}-$ C. gloeosporioides agente de controle biológico de $O$. praelonga;

CCC - C.gloeosporioides agente causal de doenças de pós-colheita em citros;

CCA - C.gloeosporioides agente causal da podridão floral dos citros.

CESNIK, R.; OLIVEIRA, G.C.G. Colletotrichum gloeosporioides, isolado de Orthezia praelonga causando patogenicidade em Coccoloba sp. In: CONGRESSO PAULISTA DE FITOPATOLOGIA, 19, 1993, Campinas. Resumos. Jaguariúna: Summa Phytopathologica, 1993. p. 37.

CESNIK, R.; FERRAZ, J.M.G. Orthezia praelonga Douglas, 1891(Hemiptera, Ortheziidae) biologia, controle químico e biológico. 
Jaguariúna: Embrapa Meio Ambiente, 2000. 27p (Boletim de Pesquisa, 09)

MUNIZ, M. de F.S.; SANTOS, R de C.R. dos.; BARBOSA, G.V. de S. Patogenicidade de Colletotrichum gloeosporioides sobre algumas plantas frutíferas. Summa Phytopathologica, Jaboticabal, v.24, p.177$179,1998$.

NARDO, E.A.B.; CAPALBO, D.M.F. Utilização de agentes microbianos de controle de pragas: mercado, risco e regulamentações. In: MELO, I.S. de; AZEVEDO, J.L. de. (Ed.) Controle Biológico: Jaguariúna. Embrapa Meio Ambiente,1998, v.1, p.231-262.
TEIXEIRA, M.A.; BETTIOL,W.; CESNIK,R. Patogenicidade do fungo Colletotrichum gloeosporioides, patógeno de Orthezia praelonga, para folhas, frutos e flores cítricas. Summa Phytopathologica, Jaboticabal, v.27, p. 352-357, 2001. 